\title{
Conversion of underwater endoscopic mucosal resection to gel immersion for the resection of a superficial non-ampullary duodenal epithelial tumor
}

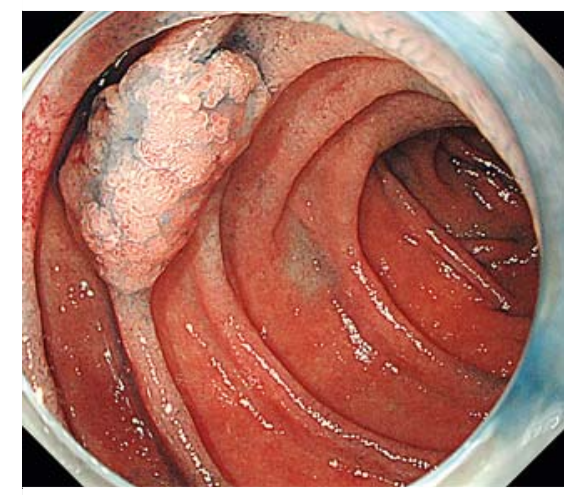

- Fig. 1 Endoscopic appearance of the tumor. A $15-\mathrm{mm}$ flat-elevated tumor is found at the superior duodenal angle.

Recently, underwater endoscopic mucosal resection (UEMR) was introduced for superficial non-ampullary duodenal epithelial tumors (SNADETs), and good treatment outcomes have been reported $[1,2]$. However, it can be difficult to maintain a sufficient amount of saline in the duodenum to soak the lesion. In some cases, the target lesion cannot be easily visualized because of the mixture of intestinal juice, blood, and saline, making accurate snaring difficult. To overcome this difficulty, we report a unique approach using a novel gel (VISCOCLEAR; Otsuka Pharmaceuticals Factory, Chiyoda, Japan), which allowed complete resection of a SNADET.

A 74-year-old woman presented with a flat-elevated tumor (diameter, $15 \mathrm{~mm}$ ) at the superior duodenal angle ( $\triangleright \mathbf{F i g}$. 1). UEMR was attempted initially. After complete deflation of the gastric and duodenal lumens, saline was injected until the lesion could be adequately visualized. This improved the maneuverability of the endoscope. However, due to strong intestinal peristalsis, air bubbles, and bile regurgitation, the endoscope came into contact with the lesion and the lesion surface started bleeding. Bile and blood mixed with saline and it be-
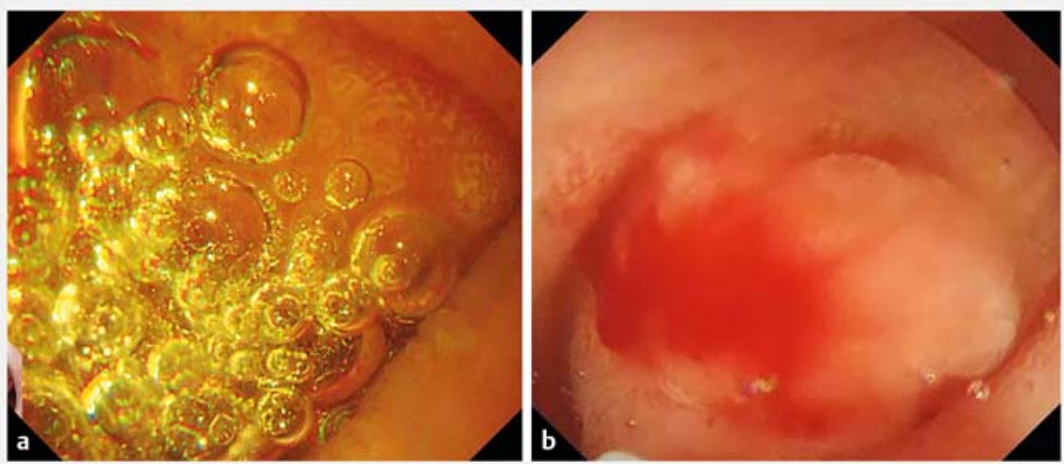

- Fig. 2 Underwater view. a Air bubbles and bile regurgitation in the area where the tumor is located. $\mathbf{b}$ Bleeding from the surface of the lesion due to contact with the endoscope.
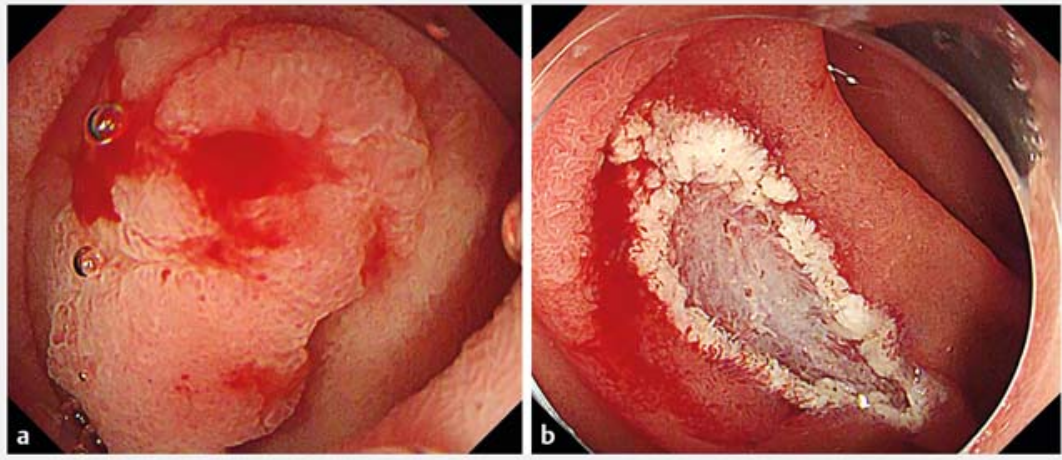

- Fig. 3 Gel immersion endoscopic mucosal resection. a Gel immersion view. The gel improved the visibility of the lesion. $\mathbf{b}$ The lesion was accurately captured by a snare (Snare Master $15 \mathrm{~mm}$, Olympus Medical System, Tokyo, Japan) and was resected without perforation and bleeding.

came difficult to visualize the lesion ( Fig. 2). Furthermore, the injected saline $(400 \mathrm{~mL}$ in total) flowed into the jejunum. UEMR was converted to gel immersion EMR ( $\triangleright$ Fig.3). Gel immersion secured clear endoscopic visualization and the lesion was completely resected without aspiration events, with large volumes of water and gel ( $\triangleright$ Fig. 4 and $\triangleright$ Video $\mathbf{1}$ ). Due to the viscous nature of the gel, it remained in the duodenum long enough that EMR could be performed easily. In total, only $160 \mathrm{~mL}$ of the gel was used. Recently, endoscopic examination and treatment of duodenal tumors using gel immersion has been performed [3-5]. Gel immersion EMR may be an alternative to UEMR for SNADET resection. 


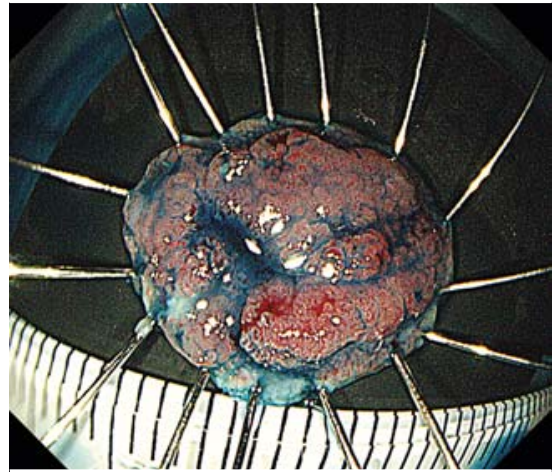

- Fig. 4 Gross appearance of the tumor. Resected specimen $(17 \times 12 \mathrm{~mm})$. Pathologically, the tumor is a non-ampullary intestinal-type adenoma with negative margins.

\section{Competing interests}

The authors declare that they have no conflict of interest.

The authors

Tomoaki Tashima', Yuya Nakano ${ }^{1}$, Tomonori Kawasaki ${ }^{2}$, Ryuhei Jinushi ${ }^{1}$, Akashi Fujita ${ }^{1}$, Yuki Tanisaka', Shomei Ryozawa' ${ }^{1}$

1 Department of Gastroenterology, Saitama Medical University International Medical Center, Saitama, Japan

2 Department of Pathology, Saitama Medical University International Medical Center, Saitama, Japan

\section{Corresponding author}

\section{Tomoaki Tashima, MD, PhD}

Department of Gastroenterology, Saitama Medical University International Medical Center, 1397-1 Yamane, Hidaka City, Saitama 350-1298, Japan

Fax: +81-42-984-4589

t.tashima1981@gmail.com

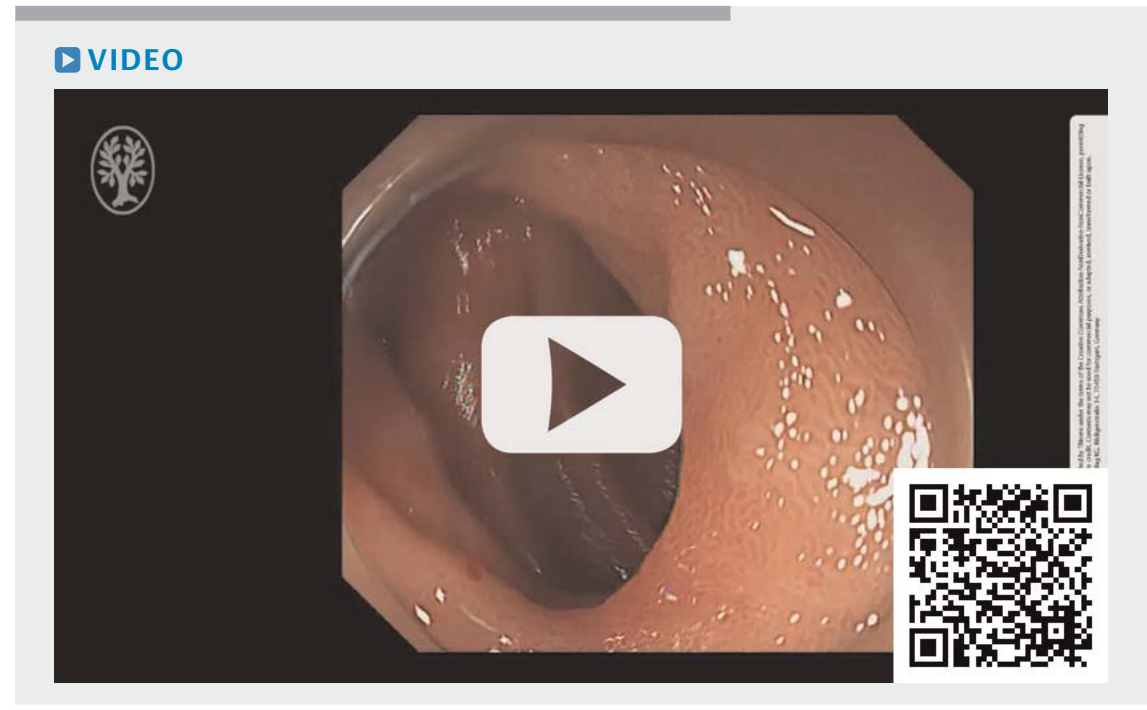

- Video 1 Underwater endoscopic mucosal resection was converted to gel immersion endoscopic mucosal resection for complete resection of a duodenal non-ampullary epithelial tumor.

\section{References}

[1] Yamasaki Y, Uedo N, Takeuchi Y et al. Underwater endoscopic mucosal resection for superficial nonampullary duodenal adenomas. Endoscopy 2018; 50: 154-158

[2] Kiguchi Y, Kato M, Nakayama A et al. Feasibility study comparing underwater endoscopic mucosal resection and conventional endoscopic mucosal resection for superficial non-ampullary duodenal epithelial tumor $<20 \mathrm{~mm}$. Dig Endosc 2020; 32: 753-760

[3] Miyamoto S, Suzuki K, Kinoshita K. Efficiency of a novel gel product for duodenal ulcer bleeding. Dig Endosc 2021; 33: e63-e64

[4] Toyonaga H, Takahashi K, Kin T et al. Gel immersion technique for the examination and treatment of an ampullary tumor. Endoscopy 2021: doi:10.1055/a-1408-0458

[5] Tashima T, Miyaguchi K, Terada R et al. Gel immersion endoscopic submucosal dissection using a novel gel product for a duodenal epithelial tumor. Endoscopy 2021: doi:10.1055/a-1443-4796

\section{Bibliography}

Endosc Int Open 2021; 09: E1924-E1925

DOI 10.1055/a-1633-3303

ISSN 2364-3722

(C) 2021. The Author(s).

This is an open access article published by Thieme under the terms of the Creative Commons Attribution-NonDerivativeNonCommercial License, permitting copying and reproduction so long as the original work is given appropriate credit. Contents may not be used for commercial purposes, or adapted, remixed, transformed or built upon. (https:// creativecommons.org/licenses/by-nc-nd/4.0/)

Georg Thieme Verlag KG, Rüdigerstraße 14, 70469 Stuttgart, Germany

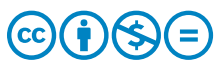

